\title{
Optimal electrocardiographic limb lead set for rapid emphysema screening
}

This article was published in the following Dove Press journal:

International Journal of COPD

18 January 2013

Number of times this article has been viewed

Rishi Bajaj'

Lovely Chhabra'

Zainab Basheer ${ }^{2}$

David H Spodick ${ }^{3}$

'Department of Internal Medicine, University of Massachusetts Medical School, Worcester, MA, USA; ${ }^{2}$ Department of Medicine, Al Ameen Medical College, Karnataka, India; ${ }^{3}$ Department of Cardiovascular Medicine, Saint Vincent Hospital, University of Massachusetts Medical School, Worcester, MA, USA
Correspondence: Lovely Chhabra 285 Plantation Street, Number 813, Worcester, MA 0I604, USA

Tel +l 5086675052

Fax +l 8885986647

Email lovids@hotmail.com
Background: Pulmonary emphysema of any etiology has been shown to be strongly and quasidiagnostically associated with a vertical frontal $P$ wave axis. A vertical $P$ wave axis ( $>60$ degrees) during sinus rhythm can be easily determined by a P wave in lead III greater than the P wave in lead I (bipolar lead set) or a dominantly negative $\mathrm{P}$ wave in aVL (unipolar lead set). The purpose of this investigation was to determine which set of limb leads may be better for identifying the vertical $P$ vector of emphysema in adults.

Methods: Unselected consecutive electrocardiograms from 100 patients with a diagnosis of emphysema were analyzed to determine the $\mathrm{P}$ wave axis. Patients aged younger than 45 years, those not in sinus rhythm, and those with poor quality tracings were excluded. The electrocardiographic data were divided into three categories depending on the frontal $\mathrm{P}$ wave axis, ie, $>60$ degrees, 60 degrees, or $<60$ degrees, by each criterion ( $\mathrm{P}$ amplitude lead III $>$ lead I and a negative $\mathrm{P}$ wave in aVL).

Results: Sixty-six percent of patients had a $\mathrm{P}$ wave axis $>60$ degrees based on aVL, and $88 \%$ of patients had a $\mathrm{P}$ wave axis $>60$ degrees based on the $\mathrm{P}$ wave in lead III being greater than in lead I.

Conclusion: A P wave in lead III greater than that in lead I is a more sensitive marker than a negative $\mathrm{P}$ wave in aVL for diagnosing emphysema and is recommended for rapid routine screening.

Keywords: electrocardiography, P wave axis, emphysema

\section{Introduction}

Emphysema of any etiology is nearly always caused by chronic obstructive pulmonary disease, and has been shown to be strongly and quasidiagnostically associated with a vertical frontal $\mathrm{P}$ wave axis. ${ }^{1-11}$ In previous investigations, we have determined that a vertical $\mathrm{P}$ wave axis ( $>60$ degrees) during sinus rhythm can be used as a lone criterion to screen for pulmonary hyperinflation/emphysema, with sensitivity and specificity both being above $90 \%{ }^{4,5,8}$ Previous studies have also suggested that the degree of $\mathrm{P}$ vector verticalization has an inverse correlation with qualitative lung function ${ }^{8,9}$ and quantification of radiographic emphysema. ${ }^{12,13} \mathrm{~A}$ vertical $\mathrm{P}$ vector on a surface 12 -lead electrocardiogram can be determined by two methods using limb leads, ie, a P wave amplitude in lead III greater than in lead I or a negative P wave in aVL, ${ }^{1,5,8}$ although both these electrocardiographic findings suggest a vertical $P$ vector and theoretically both should be simultaneously present in all the patients with a vertical $\mathrm{P}$ vector.

However, preliminary observations from our previous investigations had suggested that this is not the case in the clinical setting. Thus, the purpose of our current 
investigation was to determine which set of limb leads would be better for identifying the vertical $P$ vector of emphysema in adults, given that this has not been investigated previously. A P wave amplitude in lead III greater than in lead I indicates a $\mathrm{P}$ axis $>60$ degrees, a $\mathrm{P}$ wave amplitude in lead III equal to that in lead I indicates a $\mathrm{P}$ axis of 60 degrees, and a $\mathrm{P}$ wave amplitude in lead III smaller than in lead I indicates a $\mathrm{P}$ axis $<60$ degrees. A negative $\mathrm{P}$ wave in aVL indicates a $\mathrm{P}$ axis $>60$ degrees, while a flat or equiphasic $\mathrm{P}$ wave in aVL indicates a $\mathrm{P}$ axis of 60 degrees and a positive $\mathrm{P}$ wave in aVL indicates a $\mathrm{P}$ axis $<60$ degrees. ${ }^{1,2,5,8}$ Our plan was to conduct this investigation in patients having a known diagnosis of emphysema with a working hypothesis, that the set more often showing $\mathrm{P}$ wave verticalization would be a more sensitive (better) marker for diagnosis of emphysema. Thus, we aimed to investigate whether a $\mathrm{P}$ wave amplitude in lead III greater than that in lead I is a better marker of emphysema than an inverted $\mathrm{P}$ wave in aVL.

\section{Materials and methods}

We recorded 12-lead electrocardiograms at rest using a standard technique in unselected consecutive patients with a known diagnosis of emphysema and scheduled for a routine follow-up visit in the pulmonary clinic at our institution between March and April 2012, with the aim of obtaining a total of 100 patient electrocardiograms after application of the exclusion criteria. Inclusion criteria were age $>45$ years, ${ }^{5-9}$ normal sinus rhythm, a prior confirmed diagnosis of emphysema with a documented clinical history, chest radiographs, and pulmonary function tests. We excluded patients aged younger than 45 years, those not in normal sinus rhythm, and those with poor quality tracings. Patients younger than 45 years of age were excluded because a vertical $P$ wave axis may be a normal finding in healthy children and young adults. ${ }^{1,5,8}$ Paced rhythms were also excluded. The electrocardiograms were then analyzed individually by all the authors using a handheld loop magnifier to determine the frontal $P$ wave axis/frontal $P$ vector by accounting for the $\mathrm{P}$ wave amplitudes in leads I, III, and aVL. Any differences in individual observations were resolved by consensus in a conference. All patients enrolled in the investigation had a documented diagnosis of pulmonary emphysema supported by clinical history, chest radiographs (findings of increased radiolucency of the lungs, a flat diaphragm, and a long, narrow heart shadow), and pulmonary function tests. Pulmonary function tests showed an obstructive airway pattern (forced expiratory volume in one second/forced vital capacity ratio $\left[\mathrm{FEV}_{1} / \mathrm{FVC}\right]<0.70$ and a forced expiratory
Table I Baseline characteristics of the study population

\begin{tabular}{lll}
\hline Variable & $\begin{array}{l}\text { Emphysema } \\
\text { patients }(\mathbf{n}=100)\end{array}$ & $P$ value \\
\hline Age (in years) & $68.2 \pm 9.86$ & - \\
Males (\%) & $41 \%$ & - \\
Frontal P axis (in degrees) & $68.6 \pm 11.4$ & - \\
Smoking history (\%) & $94 \%$ & - \\
Smoking pack-years & $48.3 \pm 28.5$ & - \\
FEV $(\%)$ & $49.1 \pm 17.8$ & - \\
r (FEV, and frontal P axis) & -0.52 & $<0.00$ I \\
Verticalization of P axis & & - \\
$\quad$ By leads I and III (bipolar limb lead set) & $88(88 \%)$ & - \\
By lead aVL (unipolar limb lead) & $66(66 \%)$ & - \\
\hline
\end{tabular}

Notes: Data are represented as $n, n(\%)$, and mean \pm standard deviation; $r$ represents correlation coefficient between $\mathrm{FEV}_{1}$ and $\mathrm{P}$ axis.

Abbreviation: $\mathrm{FEV}_{1}$, forced expiratory volume in one second.

volume in one second $\left[\mathrm{FEV}_{1}\right]<80 \%$ of predicted) without significant bronchodilator reversibility. Electrocardiographic data for the 100 patients were divided into three categories depending on the frontal $\mathrm{P}$ wave axis, ie, $>60$ degrees, 60 degrees, or $<60$ degrees, by each criterion (ie, accounting for the $\mathrm{P}$ amplitude in leads III and I and the P wave in aVL). A correlation between the frontal $\mathrm{P}$ axis and $\mathrm{FEV}_{1}$ was also tested for using Pearson's correlation test.

\section{Results}

The baseline demographic characteristics of the study population are shown in Table 1. The mean ( \pm standard deviation) age of the patients was $68.2 \pm 9.9$ years, of whom $41 \%$ were male. Ninety-four percent of the patients had an active or remote smoking history, with an average of $48.3 \pm 28.5$ packyears of smoking. The mean P vector was 68.6 \pm 11.4 degrees and did bear an inverse correlation with $\mathrm{FEV}_{1}(\mathrm{r}=-0.52$; $P<0.001$ ). Of 73 study patients who had also undergone a conventional computed tomographic scan of the chest, 66 (90.4\%) had evidence of emphysematous changes. Table 2 shows the $\mathrm{P}$ wave axis based on $\mathrm{P}$ wave amplitude in leads I and III. Eighty-eight of the 100 patients had a P wave in lead III greater than the P wave in lead I, eight had a $\mathrm{P}$ wave in lead I equal to that in lead III, and four had a P wave greater in lead I than in lead III. Table 3 shows the P wave axis based on P wave morphology in aVL. Sixty-six of

Table $2 \mathrm{P}$ axis based on $\mathrm{P}$ wave morphology in leads I and III

\begin{tabular}{ll}
\hline $\mathbf{P}$ axis $(\mathbf{n}=\mathrm{I00})$ & Emphysema $(\mathbf{n})$ \\
\hline$>60$ degrees $(\mathrm{P}$ wave in lead III $>\mathrm{I})$ & $88(88 \%)$ \\
60 degrees $(\mathrm{P}$ wave in lead III $=\mathrm{I})$ & $8(8 \%)$ \\
$<60$ degrees $(\mathrm{P}$ wave in lead III $<\mathrm{I})$ & $4(4 \%)$ \\
\hline
\end{tabular}

Note: Data are represented as $\mathrm{n}$ and $\mathrm{n}(\%)$. 
Table $3 \mathrm{P}$ axis based on $\mathrm{P}$ wave morphology in lead aVL

\begin{tabular}{ll}
\hline $\mathbf{P}$ axis $(\mathbf{n}=\mathbf{1 0 0})$ & Emphysema (n) \\
\hline$>60$ degree (negative $\mathbf{P}$ wave in $\mathrm{aVL})$ & $66(66 \%)$ \\
60 degree (equiphasic $\mathbf{P}$ wave in $\mathrm{aVL})$ & $22(22 \%)$ \\
$<60$ degree (positive $\mathrm{P}$ wave in $\mathrm{aVL})$ & $12(12 \%)$ \\
\hline
\end{tabular}

Note: Data are represented as $\mathrm{n}$ and $\mathrm{n}(\%)$.

the 100 patients had a predominantly negative $P$ wave, 22 had a flat $\mathrm{P}$ wave, and 12 had a positive $\mathrm{P}$ wave in aVL. Sixtytwo patients had a $\mathrm{P}$ axis $>60$ degrees by both criteria. An electrocardiographic tracing showing $\mathrm{P}$ wave amplitude in lead III greater than in lead I and an unequivocally negative $\mathrm{P}$ wave in aVL during sinus rhythm is shown in Figure 1. The study results demonstrated that a $\mathrm{P}$ wave amplitude in lead III greater than in lead I (sensitivity 88\%) is a more sensitive marker of emphysema than an inverted $\mathrm{P}$ wave in aVL (sensitivity 66\%).

\section{Discussion}

Frontal $\mathrm{P}$ wave verticalization has been shown to have a close correlation with emphysema and has been extensively studied in previous investigations. ${ }^{1-8}$ Moreover, increasing verticality of the frontal $\mathrm{P}$ vector correlates with increasing degrees of airway obstruction, ${ }^{8,9}$ degree of depression of the diaphragm, ${ }^{3}$ and radiographic quantification of the disease. ${ }^{12,13}$ A possible mechanism of $\mathrm{P}$ wave axis verticalization in lung hyperinflation is that the right atrium is firmly attached to the diaphragm by a dense pericardial ligament around the inferior vena cava. ${ }^{3}$ With progressive flattening of the diaphragm, the right atrium is distorted/displaced inferiorly, causing a significant rightward deviation (verticalization) of the $\mathrm{P}$ wave axis. A prospective blinded investigation of patients with purely (fibrotic) restrictive, compared with purely obstructive pulmonary disease showed the $\mathrm{P}$ axis to follow the level of the diaphragm, such that patients with restrictive lung disease and high diaphragms had horizontal and leftward $\mathrm{P}$ axes, while patients with low diaphragms and obstructive lung disease had vertical $\mathrm{P}$ axes. ${ }^{3}$ In the study by Baljepally et al, ${ }^{5}$ the sensitivity and specificity of a $\mathrm{P}$ axis $>60$ degrees for emphysema was found to be $89 \%$ and $96 \%$, respectively. In another study by Chhabra et al, ${ }^{8}$ sensitivity and specificity of a vertical $\mathrm{P}$ axis for diagnosing emphysema was $94.7 \%$ and $86.4 \%$, respectively. From prior correlation studies, ${ }^{5,8}$ it is clear that a vertical $\mathrm{P}$ axis on an electrocardiogram is the single most common screening tool, which is highly sensitive and specific in diagnosing emphysema at a glance. ${ }^{5,8}$ Both studies $^{5,8}$ used electrocardiographic criteria (a P amplitude in lead III greater than in lead I and/or a dominantly negative $\mathrm{P}$ wave in aVL) to determine $\mathrm{P}$ wave verticalization. In the present study, we took this further by investigating the percentage of patients with emphysema who have a dominantly negative or inverted $\mathrm{P}$ wave in aVL compared with a P wave in lead III greater than that in lead I; $88 \%$ of the emphysema patients had a P wave in lead III greater than that in lead I, and only $66 \%$ of the patients had an inverted or negative $\mathrm{P}$ wave in aVL. In an ideal theoretical setting, the $\mathrm{P}$ wave amplitude should be negative in aVL when the P wave amplitude in lead III is greater than in lead I (suggesting a vertical $\mathrm{P}$ vector), but this was not found in a practical clinical setting, which could be possibly due to a commonly encountered variable/high skin resistance or poor surface contact at aVL producing a spurious "augmented" extremity (unipolar) lead abnormality. ${ }^{14}$ Thus, the results suggest that the bipolar lead set is more sensitive for rapid characterization of emphysema than the unipolar set.

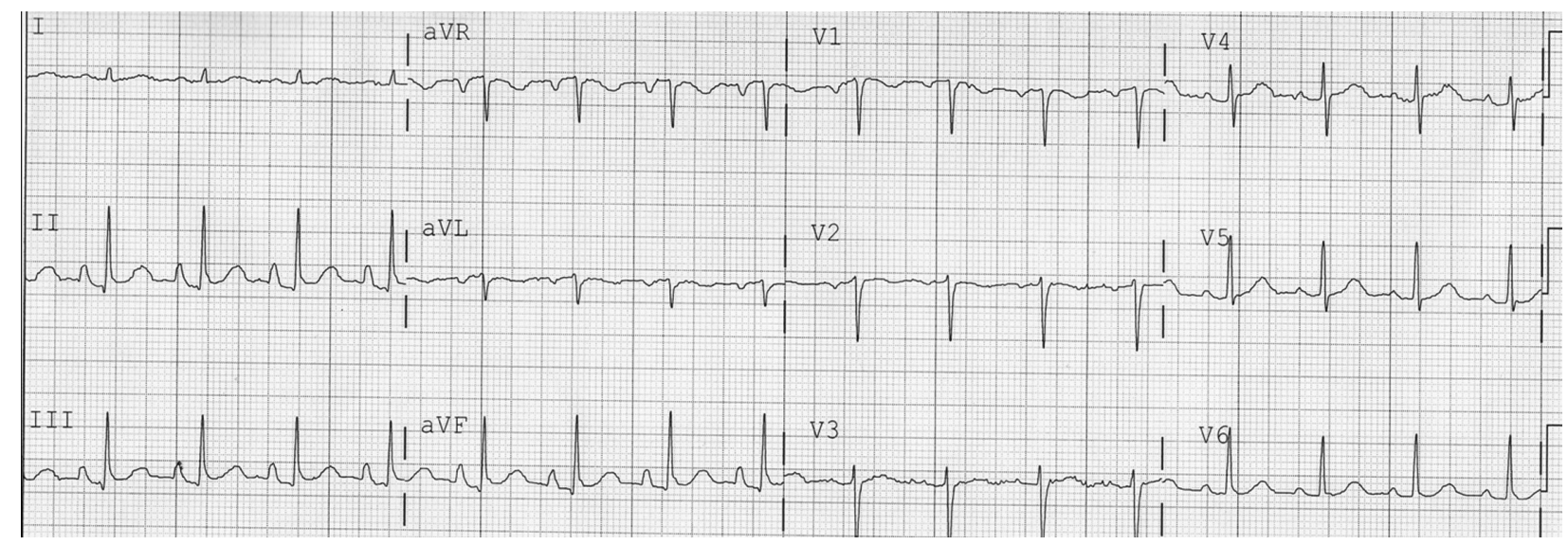

Figure I Electrocardiographic tracing representing a vertical $\mathrm{P}$ vector: $\mathrm{P}$ wave amplitude in lead III greater than $\mathrm{P}$ wave in lead I and an unequivocally negative $\mathrm{P}$ wave in aVL during sinus rhythm. 


\section{Limitations}

All patients enrolled had a known diagnosis of emphysema (based on chest radiographs and pulmonary function tests), so the specificity of both these electrocardiographic criteria for diagnosing emphysema could not be estimated in the current study. Emphysema was diagnosed based on clinical history, chest radiographs, and pulmonary function tests. High resolution computed tomographic scanning was not used to confirm the diagnosis, and is known to have a higher sensitivity and specificity for diagnosing structural emphysematous changes.

\section{Conclusion}

Electrocardiographic analysis of 100 patients with clinically documented emphysema prompted the following conclusions. The vertical $P$ axis ( $>60$ degrees) on an electrocardiogram is a unique characteristic of obstructive pulmonary disease in adults and is the single most important tool for identifying emphysema by electrocardiogram, and serves as a virtual screening test at a glance. A P wave in lead III larger than in lead $\mathrm{I}$ is a more sensitive marker for rapid identification of emphysema compared with an inverted $\mathrm{P}$ wave in aVL.

\section{Disclosure}

The authors report no conflicts of interest in this work.

\section{References}

1. Spodick DH. Electrocardiographic studies in pulmonary disease. I. Electrocardiographic abnormalities in diffuse lung disease. Circulation. 1959;20:1067-1072.
2. Zuckerman R, Cabrera CE, Fishleder BL, Sodi-Pallares D. The electrocardiogram in chronic cor pulmonale. Am Heart J. 1948;35:421-425.

3. Shah NS, Koller SM, Janower ML, Spodick DH. Diaphragm levels as determinants of $\mathrm{P}$ axis in restrictive vs obstructive pulmonary disease. Chest. 1995;107:697-700.

4. Thomas AJ, Apiyasawat S, Spodick DH. Electrocardiographic detection of emphysema. Am J Cardiol. 2011;107:1090-1092.

5. Baljepally R, Spodick DH. Electrocardiographic screening for emphysema: the frontal plane P axis. Clin Cardiol. 1999;22:226-228.

6. Littmann D. The electrocardiographic findings in pulmonary emphysema. Am J Cardiol. 1960;5:339-348.

7. Spodick DH. Electrocardiographic studies in pulmonary disease. II. Establishment of criteria for the electrocardiographic inference of diffuse lung diseases. Circulation. 1959;20:1073-1074.

8. Chhabra L, Sareen P, Perli D, Srinivasan I, Spodick DH. Vertical P-wave axis: the electrocardiographic synonym for pulmonary emphysema and its severity. Indian Heart J. 2012;64:40-42.

9. Spodick DH. Vectorcardiogram in pulmonary emphysema: its relation to scalar electrocardiographic findings. Am Rev Respir Dis. 1968;98: 634-639.

10. Chhabra L, Spodick DH. Transient Super-Himalayan P-waves in severe pulmonary emphysema. J Electrocardiol. 2012;45:26-27.

11. Zambrano SS, Moussave MS, Spodick DH. QRS duration in chronic obstructive lung disease. J Electrocardiol. 1974;7:35-36.

12. Chhabra L, Sareen P, Gandagule A, Spodick DH. Visual computed tomographic scoring of emphysema and its correlation with its diagnostic electrocardiographic sign: the frontal $\mathrm{P}$ vector. J Electrocardiol. 2012;45:136-140.

13. Chhabra L, Sareen P, Gandagule A, Spodick D. Computerized tomographic quantification of chronic obstructive pulmonary disease as the principal determinant of frontal P vector. Am J Cardiol. 2012;109: 1046-1049.

14. Schwarzschild MM, Hoffman I, Kissin M. Errors in unipolar limb leads caused by unbalanced skin resistances, and a device for their elimination. Am Heart J. 1954;48:235-248.
International Journal of COPD

\section{Publish your work in this journal}

The International Journal of COPD is an international, peer-reviewed journal of therapeutics and pharmacology focusing on concise rapid reporting of clinical studies and reviews in COPD. Special focus is given to the pathophysiological processes underlying the disease, intervention programs, patient focused education, and self management protocols.

\section{Dovepress}

This journal is indexed on PubMed Central, MedLine and CAS. The manuscript management system is completely online and includes a very quick and fair peer-review system, which is all easy to use. Visit $\mathrm{http}: / /$ www.dovepress.com/testimonials.php to read real quotes from published authors. 